\title{
Recurrent Embolic Strokes of Undetermined Source in a Patient with Extreme Lipoprotein(a) Levels
}

\author{
Zachary Bulwa ${ }^{1 *}$, Audrey Kim², Karandeep Singh ${ }^{2}$, Alexander Kantorovich ${ }^{3,4}$ and \\ Faten Suhail ${ }^{4}$ \\ ${ }^{1}$ Internal Medicine, University of Chicago - NorthShore University Health System, Evanston, IL, USA, ${ }^{2}$ Rosalind Franklin \\ University of Medicine and Science, North Chicago, IL, USA, ${ }^{3}$ College of Pharmacy, Chicago State University, Chicago, IL, \\ USA, ${ }^{4}$ Internal Medicine, Advocate Christ Medical Center, Chicago, IL, USA
}

Lipoprotein(a) is a plasma lipoprotein and known cardiovascular risk factor, most recently implicated in the development of high-risk carotid atherosclerotic plaques without significant carotid stenosis. We present a case of a young African-American female with recurrent embolic strokes of undetermined source. After our thorough investigation, we identified the link between a small, irregular plaque in the right internal carotid artery, and

OPEN ACCESS

Edited by:

Antonio Arauz,

National Institute of Neurology and

Neurosurgery, Mexico

Reviewed by:

Vincent Thijs,

Florey Institute of Neuroscience and

Mental Health, Australia

Miguel A. Barboza,

Hospital Dr. Rafael A. Calderón

Guardia, Costa Rica

*Correspondence:

Zachary Bulwa

zacharybulwa@gmail.com

Specialty section:

This article was submitted to

Stroke, a section of the journal

Frontiers in Neurology

Received: 05 July 2016

Accepted: 22 August 2016

Published: 31 August 2016

Citation:

Bulwa Z, Kim A, Singh K, Kantorovich A and Suhail $F$ (2016)

Recurrent Embolic Strokes of Undetermined Source in a Patient with Extreme Lipoprotein(a) Levels.

Front. Neurol. 7:144.

doi: 10.3389/fneur.2016.00144 an extremely elevated plasma level of lipoprotein(a) as the source of her embolic strokes.

Keywords: stroke, embolic stroke of undetermined source, cryptogenic stroke, lipoprotein(a), carotid atherosclerosis, carotid stenting

\section{CASE REPORT}

We report a case of a 46-year-old female with a past medical history significant for multiple rightsided cerebral ischemic events who was transferred from an outside hospital with acute left upper and lower extremity weakness. At the outside hospital, computed tomography (CT) imaging demonstrated an acute middle cerebral artery infarct. Due to contraindications, she did not receive tissue plasminogen activator (tPA).

Upon transfer, magnetic resonance imaging (MRI) and magnetic resonance angiography (MRA) demonstrated occlusions in the right anterior cerebral artery and middle cerebral artery, and a focal, irregular plaque in the right internal carotid artery (ICA). Cerebral angiogram redemonstrated the plaque, but no immediate intervention was recommended due to non-hemodynamically significant stenosis of less than $20 \%$ (Figure $\mathbf{1}$ ).

The patient's vitals, complete blood count, comprehensive metabolic panel, coagulation studies, and lipid panel were all within normal limits upon admission. The patient was placed on continuous cardiac telemetry. Secondary prevention was optimized by the addition of clopidogrel to the standard secondary prevention she was already receiving prior to admission, which included aspirin and atorvastatin.

One week later, the patient complained of a new onset headache. With no history of headache, precautions were taken, and a repeat MRI revealed a new infarct in the right occipital lobe and frontal lobe.

Electrocardiographic, echocardiographic (including transesophageal echocardiogram), and neuroimaging studies exhibited no major-risk cardioembolic source. Hypercoagulability workup was negative except for an extremely elevated plasma lipoprotein(a) level (414 mg/dL). The patient underwent stent placement to stabilize her vulnerable ICA plaque. She was then discharged to an acute rehabilitation facility 2 days later in stable condition. 

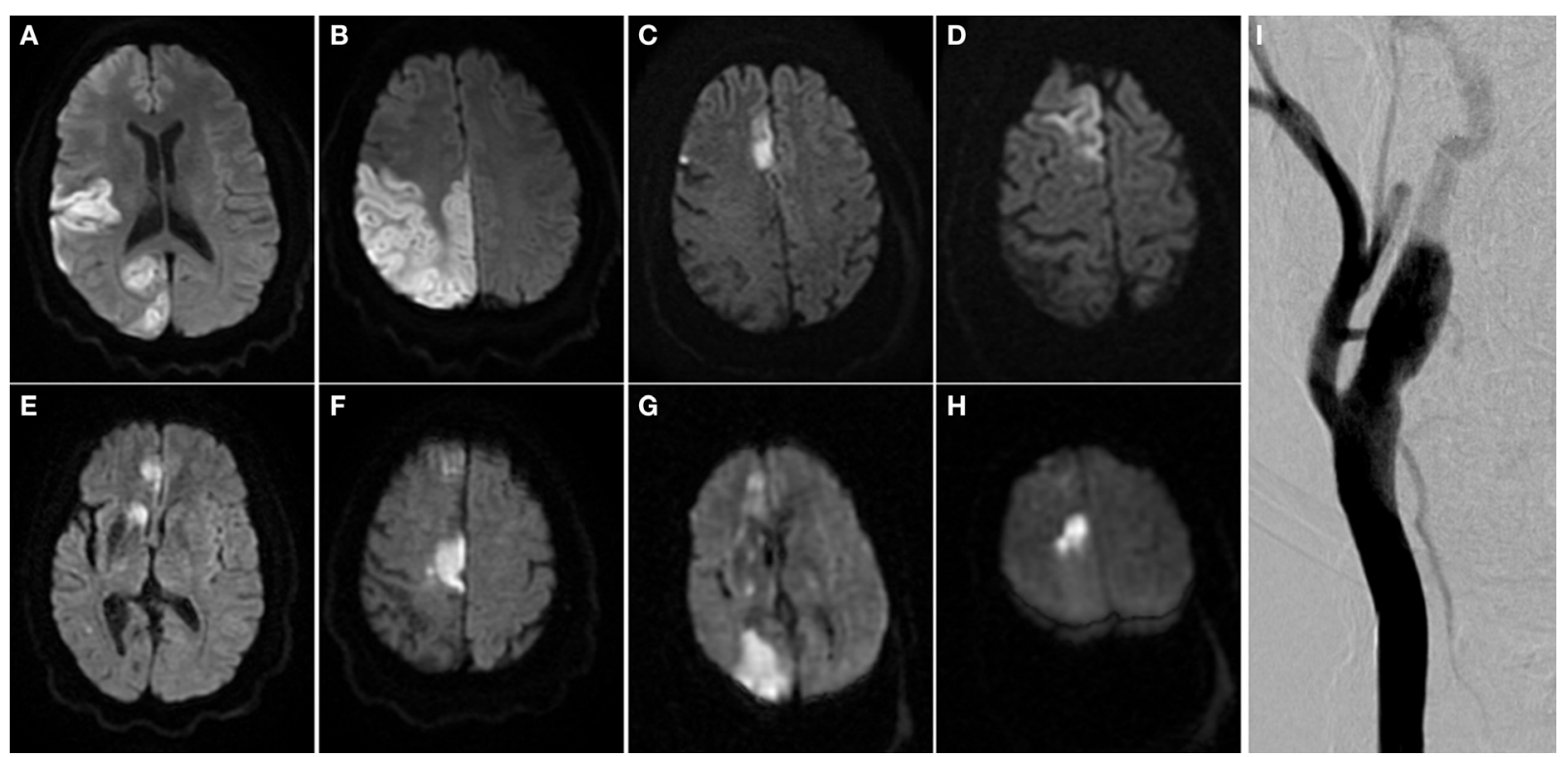

FIGURE 1 | Multiple embolic territory strokes secondary to irregular and vulnerable carotid atherosclerotic plaque. (A-H) Brain MRI scans from multiple ischemic events over multiple admissions. (I) Right carotid angiogram. Arrow indicates atherosclerotic plaque in right internal carotid artery.

\section{DISCUSSION}

We describe a young African-American female who meets criteria for recurrent embolic strokes of undetermined source (ESUS) (1). After thorough diagnostic investigation, as outlined by Nouh et al. (2), two pertinent abnormalities were found: a small, irregular plaque in the right ICA and an extremely elevated plasma level of lipoprotein(a) [Lp(a)].

Lipoprotein(a) is a known cardiovascular risk factor, but controversy surrounds its utility as a screening tool and our understanding of its pathological mechanisms (3). Lipoprotein(a) is a plasma lipoprotein consisting of a cholesterol-rich low-density lipoprotein (LDL) particle with one molecule of apolipoprotein B100 covalently linked via a disulfide bond to apolipoprotein(a) $(3,4)$. Plasma levels of $\mathrm{Lp}(\mathrm{a})$ are directly related to the variable copy number of kringle IV type $2(\mathrm{KIV}-2)$ repeats of the apolipoprotein(a) isoforms in the LPA gene $(3,4)$. Smaller isoforms of apolipoprotein(a) are associated with higher concentrations of $\operatorname{Lp}(a)(3,5,6)$. Lipoprotein(a) levels vary widely in humans, with up to $90 \%$ genetically determined via the LPA gene $(6,7)$. Individuals with smaller apolipoprotein(a) isoforms have roughly a twofold higher risk of ischemic stroke and coronary heart disease (5). Thus, there is a causal link evidenced by Mendelian randomization between genetically determined elevated levels of $\mathrm{Lp}(\mathrm{a})$ and cardiovascular disease (3-5).

Two aspects of $\operatorname{Lp}(\mathrm{a})$ make it exceptionally interesting: first, the apolipoprotein(a) co-factor is structurally homologous to plasminogen, but without fibrinolytic activity; and second, the metabolism and distribution of $\mathrm{Lp}(\mathrm{a})$ differs from that of LDL $(8,9)$. Nevertheless, the physiologic function of $\operatorname{Lp}(\mathrm{a})$ remains elusive, although its atherogenicity is thought to be due to the interference of the fibrinolytic pathway among other interactions (8).

Cerebral vascular disease, peripheral vascular disease, and most recently, carotid atherosclerosis have been associated with elevated serum levels of $\operatorname{Lp}(\mathrm{a})$ (8). These associations are independent of the levels of cholesterol and other traditional risk factors, such as age, gender, smoking, systolic blood pressure, antihypertensive medication use, diabetes mellitus, LDL cholesterol, HDL cholesterol, and triglycerides (10-12).

Virani et al. contend that elevated $\mathrm{Lp}(\mathrm{a})$ in AfricanAmericans may confer a higher risk for a cerebrovascular event than for a coronary vascular event (13). They found a positive correlation between $\mathrm{Lp}$ (a) levels and ischemic stroke at plasma levels greater than $30 \mathrm{mg} / \mathrm{dL}$ in the African-American population $(12,13)$. Most recently, Zhao et al. identified that elevated Lp(a) levels were associated with high-risk carotid atherosclerotic plaque features. Although these high-risk plaques were often seen in less severe carotid stenosis, they were vulnerable to embolization and were associated with an increased rate of strokes (14). In the ongoing CAPIAS study, which hopes to provide further insight into the role of non-stenosing carotid artery plaques, nearly half of the initially enrolled patients were found to have cryptogenic stroke as defined by TOAST criteria $(15,16)$.

The extreme plasma level of $\mathrm{Lp}(\mathrm{a})$ in combination with an irregular carotid plaque offered few therapeutic options for optimizing secondary prevention in the setting of recurrent ESUS. The promise $\mathrm{Lp}(\mathrm{a})$ holds is that, as an independent risk factor for cardiovascular disease, reducing elevated plasma levels will directly reduce cerebrovascular disease $(1,17)$. A promising 
new class of lipid-lowering drugs are the proprotein convertase subtilisin/kexin type 9 (PCSK9) inhibitors. PCSK9 regulates the catabolism of $\mathrm{Lp}(\mathrm{a})$ by inhibiting $\mathrm{Lp}(\mathrm{a})$ internalization via the LDL receptor (18). In a pooled analysis of phase II trials, PCSK9 inhibition (via evolocumab) resulted in statistically significant dose-related reductions in $\mathrm{Lp}(\mathrm{a})$, although no results have indicated a reduction of cerebrovascular events (19). And more recently, PCSK9 has been found complexed to $\operatorname{Lp}(\mathrm{a})$ particles in humans with elevated Lp(a) levels (20). It remains to be determined whether lowering $\mathrm{Lp}$ (a) levels directly will result in lower cardiovascular event rates, which may provide an additional therapeutic mechanism: antisense oligonucleotides directed against apo(a) (17). Possibly, the most compelling evidence comes from the Pro(a)Life Study Group in which chronic lipoprotein apheresis was shown to reduce the risk of recurrent cardiovascular events (and the need for carotid stenting) over a 2-year period in patients on maximally tolerated lipid-lowering therapy (21).

While long-term consideration of our patient's chronically elevated plasma Lp(a) level is critical, acute stabilization of the irregular and vulnerable carotid plaque was deemed most important due to the rapid timeline of embolic stroke recurrence. The patient was on aspirin upon admission, but no anticoagulation, consistent with recommendations from the WARSS trial (22). Although there is evidence in a subgroup analysis that warfarin may be more efficacious than aspirin among patients with cryptogenic stroke who did not have hypertension and did have embolic infarcts on neuroimaging, we did not initiate anticoagulation due to concern for an increase in major hemorrhages $(22,23)$. Currently, two trials are underway to investigate the benefit and risk of anticoagulation with direct oral anticoagulants (DOACs) compared with aspirin in patients with embolic stroke of undetermined source $(24,25)$. Due to the lack of currently available therapeutic options and probable association to the recurrent strokes, a decision was made to stabilize the carotid clot via stenting.

\section{REFERENCES}

1. Hart RG, Diener HC, Coutts SB, Easton JD, Granger CB, O'Donnell MJ, et al. Embolic strokes of undetermined source: the case for a new clinical construct. Lancet Neurol (2014) 13(4):429-38. doi:10.1016/S1474-4422(13)70310-7

2. Nouh A, Hussain M, Mehta T, Yaghi S. Embolic strokes of unknown source and cryptogenic stroke: implications in clinical practice. Front Neurol (2016) 7:37. doi:10.3389/fneur.2016.00037

3. Nordestgaard BG, Chapman MJ, Ray K, Borén J, Andreotti F, Watts GF, et al. Lipoprotein(a) as a cardiovascular risk factor: current status. Eur Heart J (2010) 31:2844-53. doi:10.1093/eurheartj/ehq386

4. Kronenberg F, Utermann G. Lipoprotein(a): resurrected by genetics. J Intern Med (2013) 273:6-30. doi:10.1111/j.1365-2796.2012.02592.x

5. Erqou S, Thompson A, Di Angelantonio E, Saleheen D, Kaptoge S, Marcovina $\mathrm{S}$, et al. Apolipoprotein(a) isoforms and the risk of vascular disease: systematic review of 40 studies involving 58,000 participants. J Am Coll Cardiol (2010) 55:2160-7. doi:10.1016/j.jacc.2009.10.080

6. Marcovina SM, Albers JJ, Wijsman E, Zhang Z, Chapman NH, Kennedy H. Differences in $\mathrm{Lp}(\mathrm{a})$ concentrations and apo(a) polymorphs between black and white Americans. J Lipid Res (1996) 37(12):2569-85.

7. Boerwinkle E, Leffert CC, Lin J, Lackner C, Chiesa G, Hobbs HH. Apolipoprotein (a) gene accounts for greater than $90 \%$ of the variation in

\section{CONCLUSION}

Considering the clinical picture, imaging, and accompanying laboratory data, it is probable that the irregular and vulnerable carotid atherosclerotic plaque contributed to recurrent ESUS. Thus, it is likely that $\operatorname{Lp}(\mathrm{a})$, in contributing to the development of the plaque, indirectly triggered these embolic infarctions. We suggest measuring $\mathrm{Lp}(\mathrm{a})$ in the workup of recurrent embolic stroke of undetermined source in the setting of non-hemodynamically significant carotid stenosis in young African-American individuals. Further study will hopefully determine the pathogenic mechanism of elevated $\mathrm{Lp}$ (a) plasma levels in order to optimize current therapies and yield new potential therapeutic targets. The recent introduction of PCSK9 inhibitors offers clinicians a novel therapeutic approach to reduce $L p(a)$ levels, but more research needs to be undertaken to evaluate cerebrovascular outcomes. Results from current randomized controlled trials in patients with ESUS will ideally illustrate the best therapeutic options in the interim $(24,25)$.

\section{ETHICS APPROVAL}

Our case report is exempt from the ethics review process as it does not involve research subjects but rather data available due to a permission form signed by the patient. This consent form allows for the publication of material relating to them in scientific and medical journals. The patient was competent and capable when signing this form.

\section{AUTHOR CONTRIBUTIONS}

All of the authors participated in the treatment of the patient. $\mathrm{ZB}$ was primarily in charge of the patient's care, while FS was the attending physician. A thorough review of the literature as well as the first draft of the manuscript was completed by ZB. All authors listed, have made substantial, direct and intellectual contribution to the work, and approved it for publication.

plasma lipoprotein(a) concentrations. JClin Invest (1992) 90(1):52-60. doi:10.1172/JCI115855

8. Kostner KM, Marz W, Kostner GM. When should we measure lipoprotein(a)? Eur Heart J (2013) 34(42):3268-76. doi:10.1093/eurheartj/eht053

9. Lentini A, Fornengo P, Bosco G, Caprioli M, Destefanis E, Cerrato P. Cryptogenic cerebral infarction in a young patient with very high lipoprotein(a) serum level as the only risk factor. Neurol Sci (2007) 28(1):42-4. doi:10.1007/s10072-007-0747-7

10. Khera AV, Everett BM, Caulfield MP, Hantash FM, Wohlgemuth J, Ridker PM, et al. Lipoprotein(a) concentrations, rosuvastatin therapy, and residual vascular risk: an analysis from the JUPITER Trial (justification for the use of statins in prevention: an intervention trial evaluating rosuvastatin). Circulation (2014) 129(6):635-42. doi:10.1161/CIRCULATIONAHA

11. Albers JJ, Slee A, O’Brien KD, Robinson JG, Kashyap ML, Kwiterovich PO Jr, et al. Relationship of apolipoproteins A-1 and B, and lipoprotein(a) to cardiovascular outcomes: the AIM-HIGH trial (atherothrombosis intervention in metabolic syndrome with low HDL/high triglyceride and impact on global health outcomes). J Am Coll Cardiol (2013) 62(17):1575-9. doi:10.1016/j. jacc.2013.06.051

12. Nasr N, Ruidavets JB, Farghali A, Guidolin B, Perret B, Larrue V. Lipoprotein(a) and carotid atherosclerosis in young patients with stroke. Stroke (2011) 42(12):3616-8. doi:10.1161/strokeaha.111.624684 
13. Virani SS, Brautbar A, Davis BC, Nambi V, Hoogeveen RC, Sharrett AR, et al. Associations between lipoprotein(a) levels and cardiovascular outcomes in black and white subjects. Circulation (2012) 125(2):241-9. doi:10.1161/ circulationaha.111.045120

14. Zhao XQ, Hatsukami TS, Hippe DS, Sun J, Balu N, Isquith DA, et al. Clinical factors associated with high risk carotid plaque features as assessed by magnetic resonance imaging in patients with established vascular disease (from the AIM-HIGH Study). Am J Cardiol (2014) 114(9):1412-9. doi:10.1016/j. amjcard.2014.08.001

15. Bayer-Karpinska A, Schwarz F, Wollenweber FA, Poppert H, Boeckh-Behrens T, Becker A, et al. The carotid plaque imaging in acute stroke (CAPIAS) study: protocol and initial baseline data. BMC Neurol (2013) 13:201. doi:10.1186/1471-2377-13-201

16. Adams HP Jr, Bendixen BH, Kappelle LJ, Biller J, Love BB, Gordon DL, et al. Classification of subtype of acute ischemic stroke: definitions for use in a multicenter clinical trial. TOAST. Trial of org 10172 in acute stroke treatment. Stroke (1993) 24(1):35-41. doi:10.1161/01.STR.24.1.35

17. Kronenberg F. Lipoprotein(a): there's life in the old dog yet. Circulation (2014) 129(6):619-21. doi:10.1161/CIRCULATIONAHA.113.007256

18. Romagnuolo R, Scipione CA, Boffa MB, Marcovina SM, Seidah NG, Koschinsky ML. Lipoprotein(a) catabolism is regulated by proprotein convertase subtilisin/kexin type 9 through the low density lipoprotein receptor. J Biol Chem (2015) 290(18):11649-62. doi:10.1074/jbc.M114.611988

19. Raal FJ, Giugliano RP, Sabatine MS, Koren MJ, Langslet G, Bays H, et al. Reduction in lipoprotein(a) with PCSK9 monoclonal antibody evolocumab (AMG 145): a pooled analysis of more than 1,300 patients in 4 phase II trials. J Am Coll Cardiol (2014) 63(13):1278-88. doi:10.1016/j.jacc.2014.01.006

20. Tavori H, Christian D, Minnier J, Plubell D, Shapiro MD, Yeang C, et al. PCSK9 association with lipoprotein(a). Circ Res (2016) 119(1):29-35. doi:10.1161/ CIRCRESAHA.116.308811

21. Leebmann J, Roseler E, Julius U, Heigl F, Spitthoever R, Heutling D, et al. Lipoprotein apheresis in patients with maximally tolerated lipid lowering therapy, lipoprotein(a)-hyperlipoproteinemia and progressive cardiovascular disease: prospective observational multicenter study. Circulation (2013) 128(24):2567-76. doi:10.1161/CIRCULATIONAHA.113.002432

22. Mohr JP, Thompson JL, Lazar RM, Levin B, Sacco RL, Furie KL, et al. A comparison of warfarin and aspirin for the prevention of recurrent ischemic stroke. N Engl J Med (2001) 345(20):1444-51. doi:10.1056/NEJMoa011258

23. Sacco RL, Prabhakaran S, Thompson JL, Murphy A, Sciacca RR, Levin B, et al. Comparison of warfarin versus aspirin for the prevention of recurrent stroke or death: sub-group analyses from the Warfarin-Aspirin Recurrent Stroke Study. Cerebrovasc Dis (2006) 22(1):4-12. doi:10.1159/000092331

24. Diener HC, Easton JD, Granger CB, Cronin L, Duffy C, Cotton D, et al. Design of randomized, double-blind, evaluation in secondary stroke prevention comparing the efficacy and safety of the oral thrombin inhibitor dabigatran etexilate vs. acetylsalicylic acid in patients with embolic stroke of undetermined source (RE-SPECT ESUS). Int J Stroke (2015) 10(8):1309-12. doi:10.1111/ijs.12630

25. Janssen LP. Rivaroxaban versus Aspirin in Secondary Prevention of Stroke and Prevention of Systemic Embolism in Patients with Recent Embolic Stroke of Undetermined Source (NAVIGATE ESUS). (2014). Available from: https://clinicaltrials.gov/ct2/show/NCT02313909

Conflict of Interest Statement: The authors declare that the research was conducted in the absence of any commercial or financial relationships that could be construed as a potential conflict of interest.

Copyright (C) 2016 Bulwa, Kim, Singh, Kantorovich and Suhail. This is an open-access article distributed under the terms of the Creative Commons Attribution License (CC $B Y)$. The use, distribution or reproduction in other forums is permitted, provided the original author(s) or licensor are credited and that the original publication in this journal is cited, in accordance with accepted academic practice. No use, distribution or reproduction is permitted which does not comply with these terms. 